\title{
Pandemias, bosques y ciencias forestales
}

\author{
Pandemics, forests and forest sciences
}

\author{
Rodrigo Arce ${ }^{1, \star}$
}

Recibido: 12 febrero 2021 | Aceptado: 16 mayo 2021 | Publicado en línea: 30 junio 2021 Citación: Arce, R. 2021. Pandemias, bosques y ciencias forestales. Revista Forestal del Perú 36(1): 4-21. DOI: http://dx.doi.org/10.21704/rfp.vli36.1702

\begin{abstract}
Resumen
El presente artículo aborda la relación existente entre pandemias y bosques y discute cómo las ciencias forestales pueden incrementar su contribución a la relación ser humano-naturaleza (bosques), a partir de una perspectiva de complejidad resignificando la orientación disciplinaria que se mantiene a la fecha. Para el efecto se ha realizado una revisión bibliográfica producida principalmente durante la crisis del COVID-19. De la revisión se concluye que las evidencias científicas sustentan una estrecha interrelación entre la alteración y degradación de los ecosistemas (incluyendo los bosques) con las pandemias. Para evitar nuevas epidemias se requiere mejorar la relación entre los seres humanos y la naturaleza (los bosques) protegiendo y respetando la diversidad de formas de vida. Existen tres aproximaciones básicas de la relación entre las ciencias forestales con los bosques: una mirada de producto, una mirada de territorio y una mirada biocéntrica, la cual consiste en respetar a todas las manifestaciones de la vida como su principal foco de pensamiento y acción. Aunque la orientación disciplinaria forestal ha sido y seguirá siendo importante para el desarrollo de las ciencias forestales, esta aproximación es insuficiente frente a la complejidad de la realidad y que tiene en los bosques un pilar fundamental. De ahí la necesidad de desarrollar las ciencias forestales desde la perspectiva de la complejidad que hace más visible las interrelaciones de los bosques como socioecosistemas entendidos como sistemas abiertos, incompletos y alejados del equilibrio. Una mirada forestal de respeto hacia todas las manifestaciones de vida aumenta enormemente su campo de acción e impacto en perspectiva de las alternativas al desarrollo o un desarrollo regenerativo con bioética forestal.
\end{abstract}

Palabras clave: Biodiversidad, complejidad, epistemología, ontología, vida

${ }^{1}$ Universidad Nacional de Ingeniería (UNI), Lima, Perú.

* Autor de Correspondencia: rarcerojas@yahoo.es 


\begin{abstract}
This paper addresses the relationship between pandemics and forests and discusses how forestry sciences can increase their contribution to the human-nature relationship (forests) from a perspective of complexity, redefining the disciplinary orientation they have maintained to date. For this purpose, a bibliographic review has been carried out, mainly during the COVID-19 crisis. From the review it is concluded that scientific evidence supports a close interrelation between the alteration and degradation of ecosystems (including forests) and pandemics, to avoid new epidemics it is necessary to improve the relationship between human beings and nature (forests) protecting and respecting the diversity of life forms. There are three basic approaches to the relationship between forestry sciences and forests: a product approach, a territorial approach and a biocentric approach, which consists of respecting all manifestations of life as its main focus of thought and action. Although the forestry disciplinary orientation has been and will continue to be important for the development of forest sciences, this approach is insufficient in the face of the complexity of reality, which has forests as a fundamental pillar. Hence the need to develop forestry sciences from the perspective of complexity that makes more visible the interrelationships of forests as socio-ecosystems understood as open, incomplete and far from equilibrium systems. A forestry approach that respects all manifestations of life increases its field of action and impact in the perspective of alternatives to development or regenerative development with forest bioethics.
\end{abstract}

Key words: Biodiversity, complexity, epistemology, ontology, life

\section{Introducción}

El presente artículo trata de la relación existente entre pandemias y bosques, y reflexiona cómo la enfermedad del coronavirus 2019 (COVID-19) originada por el virus SARSCoV-2 (coronavirus del síndrome respiratorio agudo grave tipo 2), ha causado gran impacto en todos los órdenes de la vida humana en el planeta incluyendo la relación con los bosques. El confinamiento temporal obligado en la mayor parte del mundo ha constituido una valiosa oportunidad para revisar el marco civilizatorio hegemónico, donde las ciencias forestales también han sido convocadas a través de las referencias de la destrucción de ecosistemas, la cual es una de las causas de la producción de este tipo de pandemias (Daszak et al. 2020, IRI 2020, Jeffries 2020).

Ha sido muy emotivo poder apreciar en los medios de comunicación y redes sociales imágenes del mundo donde los animales silvestres ocuparon las calles de las ciudades, repoblaron las playas, además de contemplar ríos y aire más limpios, aunque sea por el relativamente breve periodo de minimización de actividades humanas. Ello daba cuenta que son los seres humanos los que habían desplazado a los animales silvestres y no era precisamente una imagen de invasión de la naturaleza a los ambientes urbanizados (Cué 2020, Paz 2020).

De primera impresión se podría pensar que la enfermedad ocasionada por COVID-19 no tiene nada que ver con las ciencias forestales cuyo objeto de estudio refiere a los bosques en perspectiva de su conservación y aprovechamiento sostenible, no obstante, una mirada más profunda dará cuenta que la enfermedad sí tiene que ver con las ciencias forestales porque está relacionada con la alteración y fragmentación de los ecosistemas como lo sostiene el presidente de la Sociedad Española de Ciencias Forestales, Felipe Bravo, quien afirma que "la falta de una gestión forestal sostenible está relacionada con el origen de pandemias como la actual de la COVID-19" (Álvarez 2020).

La pandemia del COVID-19 no es un hecho aislado, ésta forma parte de la crisis global que se pone de manifiesto en la crisis de la pérdida (o exterminio) de la biodiversidad y la crisis climática, las cuales están interrelacionadas y que tienen un origen común en la forma cómo la humanidad se ha relacionado con la naturaleza especialmente desde la Revolución 
industrial a la fecha. Como refieren Daszak et al. (2020:3):

El cambio de uso del suelo crea efectos sinérgicos con el cambio climático (pérdida de bosques, efectos de isla de calor la quema de bosques para despejar la tierra) y la pérdida de biodiversidad que a su vez ha provocado importantes enfermedades emergentes.

Pero no solo se trata de que la alteración y degradación de ecosistemas está originando la liberación de los virus, sino que la propia pandemia genera una crisis económica que está provocando que pobladores urbanos vean en las tierras boscosas la oportunidad para desarrollar sus medios de vida y no precisamente a través de actividades productivas sustentables.

Aunque existen publicaciones especializadas, como por ejemplo las del The Intergovernmental Science-Policy Platform on Biodiversity and Ecosystem Services (IPBES) (Daszak et al. 2020) o WWF (Jeffries 2020, Pratesi et al. 2020), que dan cuenta de las relaciones entre pandemias y ecosistemas desde las ciencias forestales no se han profundizado estos nexos en términos de sus alcances para que sean aprovechados por los ejecutores vinculados al sector forestal en el Perú, más allá del protocolo sanitario para el desarrollo de las actividades productivas orientadas a la reactivación económica (Resolución Ministerial 152-2020-MINAGRI).

Es propósito del presente artículo dar cuenta de la relación entre bosques y pandemias y aprovechar las reflexiones gestadas durante el confinamiento para expandir el panorama de actuación de las ciencias forestales. El artículo permitirá reconocer que las relaciones entre las pandemias y los bosques es más estrecha de lo que en primera instancia se podría intuir. Para ello se incorpora una discusión sobre las ciencias forestales en perspectiva de complejidad que trata de una mirada de sistemas abiertos y de interrelaciones de aspectos tangibles e intangibles de la realidad entrelazada.

\section{Materiales y Métodos}

Para la elaboración de la presente investigación se realizó una búsqueda de artículos en Google Scholar y ProQuest, publicaciones de reflexión y posición generados desde diferentes perspectivas disciplinarias, informes de entidades internacionales tanto públicas como privadas. Las palabras de búsqueda fueron pandemia, naturaleza y bosques. Para el desarrollo del artículo se han empleado tres preguntas que han guiado el proceso reflexivo: ¿Qué se ha aprendido en términos de la relación entre bosques y pandemias? ¿Qué implicancias tiene la perspectiva disciplinaria de las ciencias forestales en el contexto de los retos de estos tiempos? ¿De qué manera las ciencias forestales podrían ampliar su contribución a las alternativas al desarrollo? Se entiende a las alternativas al desarrollo como aquellas propuestas que superan las concepciones tradicionales de desarrollo con alta primacía de la dimensión económica, y que valoran las diversas manifestaciones del buen vivir o la vida plena en armonía con la naturaleza desde una perspectiva de sustentabilidad fuerte.

Para el efecto se ha organizado la línea argumentativa en las siguientes secciones: reflexiones derivadas de la crisis, la raíz de la crisis, el carácter disciplinario de las ciencias forestales, las orientaciones de las ciencias forestales, los alcances de la biodiversidad, y los retos. Se realizan discusiones y se extraen conclusiones.

\section{Resultados}

\section{Reflexiones derivadas de la crisis}

Como es sabido la enfermedad por COVID-19 derivó en una pandemia de dramáticas consecuencias para la humanidad. El confinamiento obligatorio inicial y el encierro voluntario posterior ha llevado a la humanidad a un profundo proceso de reflexión en todos los campos de la actividad humana y aunque no es seguro el rumbo que se seguirá lo que sí es cierto es que la impronta dejada por esta crisis será difícil de soslayar. En tanto el origen de la pandemia del COVID-19 está asociado a la alteración y fragmentación de ecosistemas las ciencias forestales se ven convocadas en este proceso de reflexión y generación de propuestas. Si no se aprovecha esta oportunidad para repensar la forma de relacionarse con 
la naturaleza es previsible que puedan aparecer en el futuro nuevas pandemias sin previo aviso (Campanella 2020, Santos 2021). En tal sentido las ciencias forestales pueden contribuir a un mejor entendimiento de las implicancias de la mala gestión de los paisajes y ecosistemas forestales en la generación de pandemias y así poder generar recomendaciones orientadas a la previsión.

Las reflexiones llevan incluso a repensar el modelo civilizatorio y la forma cómo nos hemos relacionado con la naturaleza (Chomsky 2020). Para Boff (2020:38) una de las principales lecciones de la pandemia es que la humanidad no puede continuar con la forma de vida que ha llevado hasta ahora, no puede seguir con el mismo comportamiento marcadamente utilitarista de la naturaleza pues caso contrario la tierra tomará medidas para librarse de un miembro tan agresivo para el sistema-vida. De ahí al llamado a ser parte del pensamiento y acción transformadores para la construcción de una civilización respetuosa de la naturaleza de la cual el ser humano forma parte (Tarazona 2020).

La pandemia del COVID-19 ha puesto de manifiesto una quebrantada relación con la naturaleza (IRI 2020). Como señalan Robinson y Walzer (2020:1), la salud y el bienestar de los humanos, los animales, las plantas y el ambiente guardan una estrecha relación y sufren el hondo influjo de las actividades humanas. En ese mismo sentido Altieri y Nicholls (2020:1) manifiestan que "como nunca antes, la pandemia de coronavirus nos revela la naturaleza sistémica de nuestro mundo: la salud humana, animal y ecológica están estrechamente vinculadas". De acuerdo con FAO (2020:4), "la degradación y pérdida de los bosques es uno de esos factores que contribuyen a perturbar el equilibrio de la naturaleza y a aumentar el riesgo y la exposición de las personas a las enfermedades zoonóticas". En el mismo sentido, Hidalgo (2020:11) señala que la destrucción de las zonas forestales, para destinar el terreno a actividades agropecuarias, puede provocar la aparición de enfermedades al favorecer el contacto entre humanos y animales silvestres.

\section{La raíz de la crisis}

Para poder entender las causas de la crisis global, que da cuenta de las interrelaciones entre la crisis sanitaria, crisis climática y crisis de la biodiversidad, es necesario remitirse al marco ontológico y epistémico de cómo se ha llegado a esta situación que ha puesto a la humanidad en una situación precaria y vulnerable.

La ontología dominante en la actualidad manifiesta que el ser humano es distinto y superior a la naturaleza y que ésta ha sido hecha para ser dominada y explotada en beneficio del interés humano (Faccendini 2019). En contraste hay posiciones que reclaman el reconocimiento que la naturaleza no nos pertenece, sino que nosotros los seres humanos somos los que pertenecemos a ella y como madre le debemos amor y respeto (Santos 2020:85). Como menciona Maldonado (2020a) concebir la vida de los seres humanos al margen del resto de la trama de la vida es una abstracción errónea que ha traído consigo desastrosas consecuencias como la sexta extinción en masa, el calentamiento global y la crisis climática. Pero es importante darse cuenta que no todos los pueblos del mundo establecen una relación de dominio con la naturaleza y por el contrario existen ontologías relacionales donde la naturaleza adopta la figura de madre, amiga o de la vida misma (Maldonado 2020b:87). De estos pueblos la humanidad tiene mucho que aprender, aunque paradójicamente sean considerados como sociedades no modernas.

Para muchos autores el origen de la agresión hacia la naturaleza se encuentra en el espíritu del capitalismo (Chomsky 2020, Santos 2020). Por su parte, Harvey (2020:94) señala que el sobreconsumo ha desempeñado un papel de primera importancia en la degradación ambiental planetaria. Como afirma Maldonado (2020b:116) "el sistema económico productivista dominante ha afectado seriamente a la biosfera, incluyendo los ciclos biogeoquímicos, lo que amenaza con la sexta extinción en masa". De ahí que se hable de la necesidad de un pos-capitalismo que contenga componentes de justicia social y justicia ambiental (Varoufakis 2020). 
Existen diferentes interpretaciones sobre la manifestación de la pandemia, para algunos es la venganza de la naturaleza y para otros es simplemente un acto de defensa de la naturaleza frente a los embates de la humanidad (Santos 2020:65). En ese contexto, Gabriel (2020:131) se pregunta ¿Es el coronavirus una respuesta inmune del planeta a la insolencia del ser humano, que destruye infinitos seres vivos por codicia?

Harvey (2020:82) considera que no se puede hablar de la "naturaleza" como algo exterior y separado de la cultura, la economía y la vida diaria y que es necesario adoptar una relación más cercana con la naturaleza. En esa misma dirección, la SCDB (2020:2) señala que la pandemia:

Ha puesto de relieve aún más la importancia de la relación entre las personas y la naturaleza y nos recuerda a todos las profundas consecuencias para nuestro propio bienestar y supervivencia que pueden ocasionar una continua pérdida de diversidad biológica y degradación de los ecosistemas.

La FAO (2020) recuerda que la salud y el bienestar humano están estrechamente relacionados con los bosques quienes proveen alimentos, medicinas, agua, aire y representan valores culturales y espirituales para diversos pueblos del mundo. No es de extrañar entonces que haya cobrado relevancia el enfoque de "Una Sola Salud" (One Health) que busca integrar a la salud humana, animal y ambiental, interrelacionándolas con diversos aspectos, por ejemplo, el agro-alimentario (Cortés 2020, Pratesi et al. 2020).

Aunque el antropocentrismo sigue predominando en la mentalidad occidental han ido emergiendo corrientes biocéntricas y ecocéntricas que tienen manifestaciones en el ambientalismo inclusivo, ambientalismo integral o ecología integral en el que el ser humano se relaciona con la naturaleza desde la pertenencia y no desde la ajenidad o desde la exterioridad (Faccendini 2019). Como señala Campanella (2020:877), la humanidad ha progresado al inclinar tanto la naturaleza a nuestra volun- tad que a veces olvidamos nuestro propio lugar en ella, pero cualquier pelea del ser humano con la naturaleza la lleva perdida el ser humano (Maldonado 2021a:201).

Es necesario recordar que los virus forman parte de los ecosistemas y el hecho que cada vez existan posibilidades de espacio y temporalidad compartida con los seres humanos, como los mercados, zonas de cría y mascotas, estarían haciendo posible que algunos puedan dar un salto y deriven en patógenos (Moutou 2020). Como señala (Jeffries 2020:4):

La probabilidad de que patógenos como virus se transmitan de animales silvestres y domésticos a los seres humanos puede incrementarse por la destrucción y la modificación de ecosistemas naturales, el comercio ilegal o incontrolado de especies silvestres y las condiciones antihigiénicas bajo las cuales especies silvestres y domésticas se entremezclan y se comercializan.

El consumo de animales silvestres, aunque importante en la historia de la civilización humana en la provisión de proteínas y en el propio proceso evolutivo, también implica riesgos a la salud humana y a la propia salud de los ecosistemas en tanto puede haber casos específicos en los que se esté superando la tasa de reproducción (Tarazona 2020).

\section{El carácter disciplinario de las ciencias fores- tales}

Históricamente las ciencias se han organizado en disciplinas para facilitar el conocimiento a través del análisis de campos de estudio. No hay duda de que una mirada disciplinaria especializada es importante y necesaria porque permite profundizar el conocimiento. Basta reconocer los grandes aportes que se han dado, por ejemplo en la Dendrología en el Perú para un mejor conocimiento de la flora ligada al desarrollo forestal (Reynel et al. 2020). El tema es que el conocimiento disciplinario es insuficiente cuando se trata de abordar los grandes problemas forestales del país y del planeta, problemas de carácter complejo para los cuales las perspectivas disciplinarias muestran sus límites. A ello se suman los enfoques de la administración pública caracterizadas por la sec- 
torialidad y la falta de articulación horizontal y vertical con la sociedad civil y el sector privado.

Las ciencias forestales se cobijan en el marco de la ciencia normal, clásica o estándar por eso se caracteriza por ser dualista, determinista, mecanicista y reduccionista. Ello provoca que las ciencias forestales sean tratadas y desarrolladas como si fueran un sistema cerrado desconectado de la realidad de la cual forma parte. No es de extrañar entonces que las ciencias sociales y las humanidades sean insuficientemente tratadas en las mallas curriculares de las facultades forestales (pocos cursos relativos a los socioecosistemas tales como Sociología y cultura peruana, Antropología Rural y Amazónica, Ética, entre otros) (Arce, 2018:108). Pero esto no ha sucedido así en todas las disciplinas (por ejemplo, Ecología y Biología). El hecho que desde las perspectivas disciplinarias no era suficiente para explicar la realidad generó que aparezcan una serie de disciplinas híbridas. En el caso de ecología se mencionan la Ecología Social, la Ecología Política y corrientes de pensamiento como la ecología antropológica, ecología integral, la ecología profunda, entre otras. En el caso de la biología se tiene la Biología Celular, Biología Molecular, Biología del Desarrollo, Biología Computacional, Biología de Sistemas, Biología Cuántica, Biología de Redes, Biología Sintética entre otras. Adicionalmente se cuentan con disciplinas y corrientes de pensamiento que recuperan el valor de la vida como eje central de su reflexión tales como el Biodesarrollo, Bioeconomía, Biopolítica, Bioeconomía, Bioderecho, y la Bioética (Maldonado 2012, 2018).

Además, es necesario dar cuenta de ciencias de naturaleza interdisciplinaria tales como la Biología de la Conservación, Geografía, Historia Ambiental, Ciencias de la Tierra, entre otras. El cuadro 1 muestra las diferencias entre las ciencias forestales convencionales y las ciencias forestales en perspectiva de complejidad que alude a las ciencias y a la filosofía, ocupándose del estudio de la realidad entrelazada desde la indeterminación, no linealidad, los eventos raros, las crisis, el caos, la aleatoriedad y el azar, solo por señalar algunas de los fenómenos. A diferencia de una perspectiva analítica de la ciencia normal las ciencias de la complejidad son ciencias de síntesis (Maldonado y Gómez 2011, Maldonado 2015). Las ciencias de síntesis, a diferencia de las ciencias analíticas, no tienen objetos de estudio sino problemas de frontera, llamados así porque para abordarlos necesitan la concurrencia de diversas teorías, enfoques y métodos más allá de las disciplinas tradicionales.

En el caso de la forestería no existe propiamente dicho disciplinas sino enfoques de trabajo vinculados a la forestería social, forestería comunitaria y forestería urbana entendidos como campos aplicativos, pero sin que lleguen a constituirse como disciplinas híbridas. Aquí se entiende por ejemplo que la forestería social es aquella dirigida a trabajos de reforestación con participación de comunidades locales y la forestería comunitaria se refiere a las actividades de aprovechamiento y conservación en bosques de comunidades nativas y campesinas. El uso ligero del concepto de forestería comunitaria ha provocado casos en los que existen empresas forestales que trabajan en los bosques de las comunidades, y tienen el verdadero control de la operación, suspicazmente reciban el nombre de forestería comunitaria, aunque son las empresas las que terminan beneficiándose de las facilidades supuestamente pensadas a favor de las comunidades.

Asimismo, en el Perú no se ha desarrollado una forestería familiar que atienda las características de propietarios individuales (predios familiares). Tal es así que en el país no es posible reconocer la categoría de campesinos forestales, es decir agricultores que hacen de la producción forestal su principal medio de vida. Lo que se tiene son productores o agricultores (lo que incluye los que anteriormente se denominaban colonos) con algunas actividades complementarias ligadas a los bosques. Algo distinto es el caso de los castañeros cuya principal actividad es (o era) la recolección de la castaña (Bertholletia excelsa Bonpl.) pero que ahora pueden desarrollar algunas actividades agrícolas e incluso de extracción de madera en mayor o en menor intensidad con diversos grados de impacto sobre la sustentabilidad ecológica. 


\begin{tabular}{|c|c|c|}
\hline Categorías & Ciencias Forestales & $\begin{array}{c}\text { Ciencias Forestales en } \\
\text { perspectiva de complejidad }\end{array}$ \\
\hline Orientación disciplinaria & Disciplinaria & Interdisciplinaria, indisciplinaria \\
\hline Objeto de estudio & Los bosques & $\begin{array}{l}\text { Los problemas de frontera que } \\
\text { involucran a los bosques }\end{array}$ \\
\hline Tipo de ciencia & Normal o estándar & Posnormal \\
\hline Caracterización & $\begin{array}{l}\text { Dualista } \\
\text { Determinista } \\
\text { Mecanicista } \\
\text { Reduccionista }\end{array}$ & $\begin{array}{l}\text { No determinista } \\
\text { No lineal } \\
\text { Impredecible } \\
\text { Irreductible }\end{array}$ \\
\hline Epistemología & Cartesiana & Compleja \\
\hline Estrategia metodológica básica & Análisis & Síntesis \\
\hline Ontología & $\begin{array}{l}\text { Disyuntiva: El ser humano es } \\
\text { distinto de la naturaleza }\end{array}$ & $\begin{array}{l}\text { Relacional: El ser humano y la } \\
\text { naturaleza forman parte de una } \\
\text { misma realidad entrelazada }\end{array}$ \\
\hline Perspectiva ética fundamental & Antropocéntrica & Biocéntrica y Ecocéntrica \\
\hline Enfoque central & $\begin{array}{l}\text { De productos (bienes y servicios } \\
\text { de los bosques) }\end{array}$ & $\begin{array}{l}\text { Problemas complejos derivados } \\
\text { de los bosques (Cambio o crisis } \\
\text { climática, pérdida o exterminio de } \\
\text { la biodiversidad, entre otros) }\end{array}$ \\
\hline Interés central & $\begin{array}{l}\text { Actividades de aprovechamiento } \\
\text { y conservación de los bosques } \\
\text { que contribuyan al crecimiento } \\
\text { económico y el bienestar de la } \\
\text { población }\end{array}$ & $\begin{array}{c}\text { La convivencia y el respeto entre } \\
\text { todas las manifestaciones de vida } \\
\text { incluyendo la vida humana y la no } \\
\text { humana }\end{array}$ \\
\hline Temporalidad & $\begin{array}{l}\text { Fundamentalmente el corto y } \\
\text { mediano plazo }\end{array}$ & Corto, mediano y largo plazo. \\
\hline Visión de desarrollo & Desarrollo Sostenible & Alternativas al Desarrollo \\
\hline
\end{tabular}

Cuadro 1. Diferencias entre las ciencias forestales convencionales y las ciencias forestales en perspectiva de complejidad.

Las ciencias forestales inscritas en la perspectiva disciplinaria tienen afinidad con la biología, ecología y economía fundamentalmente. Las ciencias forestales en perspectiva de complejidad tienen amplios grados de libertad para acudir a realizar intercambios con todas las disciplinas necesarias e incluso a ingresar a procesos de interdisciplinariedad e indisciplinariedad. En tal sentido, las ciencias forestales tienen mayor apertura con todos los campos de estudios que se dediquen a la vida desde todos los ángulos. Así las perspectivas de Biodesarrollo, Bioeconomía, Biopolítica y Bioética son bienvenidas.

La necesidad de ampliar la mirada se traduce en las diversas facultades ligadas a las ciencias forestales. Nuestro país cuenta con facultades de Ciencias Forestales (Universidad Nacional Agraria La Molina), facultades mixtas como Ciencias Forestales e Ingeniería Ambiental (Universidad Nacional del Centro), facultades que tienen uno de sus ejes a las ciencias forestales tales como las Facultades de Recursos Naturales Renovables (Universidad Nacional Agraria de la Selva), Agroforestal y Acuícola (Universidad Nacional Intercultural de la Amazonía) e Ingeniería Agroforestal y Econegocios (Universidad Científica del Sur).

De todo lo anteriormente mencionado se desprende que las ciencias forestales han mantenido su mirada especializada y no ha seguido la dinámica que se puede apreciar en otras 
disciplinas afines. Campos que vinculan las ciencias forestales con la filosofía, con la ética, la epistemología o la ontología, aunque existen, todavía son marginales y no aparecen en los debates sobre desarrollo forestal (Arce 2019a, 2019b, 2020a, 2020b, 2020c, 2020d).

\section{Las orientaciones de las ciencias forestales}

Las facultades forestales y afines en el país tienen fundamentalmente una mirada de producto (bienes y servicios de los bosques) con pretensión de contribución al crecimiento económico y el bienestar social en el marco del desarrollo sostenible como paradigma de actuación. No obstante, existe la necesidad de ampliar la mirada de territorio hacia una perspectiva de desarrollo territorial sostenible y apreciar la vida en todas sus manifestaciones en el marco de las alternativas al desarrollo que ponen énfasis en la colaboración y la convivialidad como ejes de una perspectiva de biodesarrollo. Como señalan Daszak et al. (2020), se requieren cambios en los modelos de producción, comercio y de consumo, los cuales son insostenibles y actualmente perturban la naturaleza y aumentan el contacto entre la vida silvestre, el ganado, los patógenos y las personas, originando las pandemias. La Figura 1 muestra la diversidad de orientaciones posibles de las ciencias forestales y su articulación al desarrollo.
Como afirman Daszak et al. (2020), la planificación del uso de la tierra y el suelo, la gestión adaptativa de los ecosistemas y el desarrollo de condiciones adecuadas para la vida humana pueden convertirse en la clave para prevenir la propagación de enfermedades en el futuro. De ahí la importancia de los enfoques de desarrollo territorial sostenible y de los enfoques de gestión de paisajes forestales sostenibles en la orientación de las ciencias forestales. Aunque en el caso peruano existen políticas públicas orientadas al desarrollo territorial sostenible, la gestión de los paisajes forestales, el ordenamiento ambiental, la zonificación forestal en los que se recoge el principio de gestión ecosistémica en la práctica hay dificultades de implementación precisamente por el carácter sectorial de la administración pública. Esta es una oportunidad para que las ciencias forestales tengan una contribución más decidida y contundente en las estrategias de desarrollo rural, lucha contra la pobreza, agricultura familiar, seguridad y soberanía alimentaria, gestión de cuencas, gestión de recursos hídricos, entre otros. Como una anotación de pie de página se menciona que no todos los pueblos y culturas se relacionan con la naturaleza como "recursos naturales."

El desarrollo de las ciencias forestales con orientación hacia la vida no es una contradic-

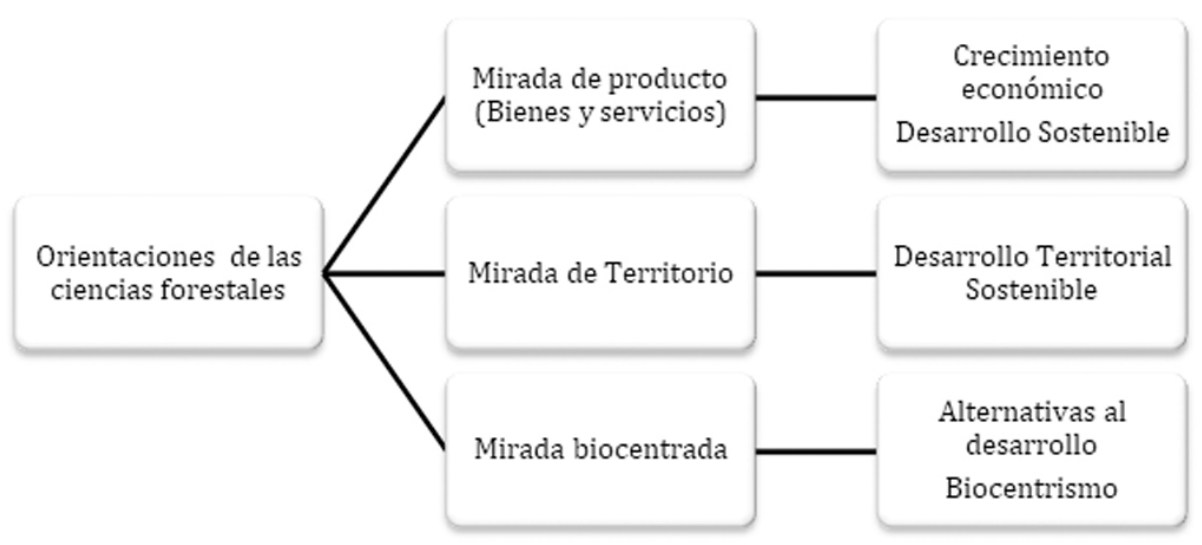

Figura 1. Diversidad de orientaciones posibles de las ciencias forestales y su articulación al desarrollo. 
ción. No es solo que la especialidad de conservación de "recursos forestales" esté preocupada por la biodiversidad forestal, sino que las consideraciones de respeto a la vida en todas sus expresiones están presentes (o deberían estar) en el manejo forestal y en las industrias forestales. En teoría es el propio manejo forestal el que debe garantizar el respeto a la vida en todas sus manifestaciones, pero en la práctica en muchas ocasiones la mirada se reduce a la conservación de los bosques de alto valor de conservación (BAVC) u otras medidas silviculturales específicas como parte de las exigencias para el cumplimiento de la legislación forestal. El respeto a la vida silvestre es consustancial a una bioética forestal. Ello no significa vetar las actividades productivas sino realizarlo con un sentido profundo de sustentabilidad ecológica y no supeditarlo únicamente a la rentabilidad económica. Eso requiere muy buena ciencia y muy buena bioética forestal.

Cuando se habla de un biocentrismo se aclara que se refiere a la valoración y respeto de todas las manifestaciones de vida humana y no humana en el mismo nivel. Esto está a tono con las propuestas actuales que ponen en relaciones de equidad al ser humano y la naturaleza, basados en la constatación que con propuestas anteriores (la naturaleza al servicio del ser humano o el ser humano al servicio de la naturaleza) se produjeron situaciones fundamentalistas en los que se consideraba que uno era mejor que el otro. En tal sentido la propuesta biocéntrica no es antihumanista como algunos grupos pretenden entender.

La posición que se adopte frente al tipo de forestería a implementar tiene repercusión. Por ejemplo, desde una perspectiva más focalizada las ciencias forestales tienen mayor vinculación con el Objetivo 15 de los Objetivos de Desarrollo Sostenible de las Naciones Unidas - ODS (vida de ecosistemas terrestres) y en grado descendiente con el objetivo 13 (Acción por el clima) y con menor importancia con el objetivo 11 (ciudades y comunidades sostenibles) (Farpón 2018).

Los demás objetivos aparecen como áreas indirectas e incluso se consideran que no tienen relación con las ciencias forestales. Pero si se plantea el enfoque desde una mirada de las ciencias forestales indisciplinarias (es decir no reducida a la disciplina) el reconocimiento del papel de los bosques en los ciclos del agua $y$ del carbono, en la provisión de productos nutracéuticos, en la lucha contra la pobreza y las desigualdades, beneficiando la salud y el bienestar de las personas, la paz social, entre otros, se puede apreciar con mayor nitidez la estrecha vinculación con los otros objetivos del desarrollo sostenible (Farpón 2018). Como afirma la FAO (2020) cada vez se reconoce más las contribuciones de los bosques a los numerosos desafíos del desarrollo sostenible. En esta misma perspectiva la Convención Americana sobre Derechos Humanos en su artículo 11 señala que todos los derechos humanos son interdependientes y exigibles sin consideración jerárquica alguna (Castro, 2021). Por lo tanto, los derechos ambientales tienen tanta importancia como los derechos sociales, económico y culturales.

Aunque los ODS son un gran avance, el problema es que no buscan otra cosa que hacer sostenible el sistema de libre mercado y el modelo antropocéntrico (Maldonado 2020:117). Se señala además que los ODS no dice nada sobre la comunidad de vida dejando en abandono a los otros seres vivos no humanos que también necesitan a la biosfera y a la sostenibilidad (Gligo et al. 2020).

La conservación de la biodiversidad forestal no es un tema que le compete exclusivamente al Ministerio del Ambiente pues es un asunto transversal a toda la administración pública en tanto es la base para la economía nacional más allá de la mirada de productos forestales. Los bosques como es sabido tienen que ver con el oxígeno, con el agua y en esa perspectiva toda la sociedad está interrelacionada. Las divisiones entre manejo forestal, industrias forestales y conservación de la naturaleza en las facultades forestales no son las más pertinentes porque crean parcelas de conocimiento que no se integran. Entre las diversas posibilidades de integración se mencionan: mayor flexibilidad para desarrollar cursos, proyectos de investigación y 
de ejecución que impliquen la concurrencia de estudiantes y docentes procedentes de manejo forestal, industrias forestales y de conservación. Asimismo, se podría alentar que en una proporción especificada por las autoridades académicas se pueda promover mayor libertad curricular para tomar algunos cursos de otras facultades de la misma universidad o de otras universidades.

De otro lado, el manejo forestal con bases científicas y éticas requiere de una buena biología, una buena ecología, una buena genéti$\mathrm{ca}$, pero además una buena base en ciencias sociales y ciencias políticas porque el manejo forestal no se reduce a dimensiones de gestión de elementos e interacciones biofísicas, sino remite a sistemas socioecológicos (es decir que reconoce las interacciones entre el subsistema social y el subsistema ecológico). Las mejores prácticas e intenciones de gestión ecológica de los bosques se ven limitadas, por ejemplo, cuando se inscriben en procesos de débil gobernanza e institucionalidad.

\section{La Biodiversidad y la diversidad biológica forestal}

Aunque en general las ciencias forestales están vinculadas a la biodiversidad hay una fuerte tendencia de los actores involucrados en el sector forestal a pensar que es un tema propio de quiénes se dedican a la conservación de los recursos forestales y no tanto para los que se dediquen al manejo forestal y a las industrias forestales. En todo caso la mirada del manejo forestal se reduce fundamentalmente a ver la diversidad de especies forestales como reales o potenciales fuentes de recursos para el desarrollo económico y a las consideraciones ecológicas para garantizar el mantenimiento de los procesos ecológicos de los bosques (composición, estructura y funciones) aunque con diversos grados de compromiso y consistencia. Existe una concepción errónea que señala que mientras más uno se aleja del trabajo de campo en los bosques, menos vínculos se tienen con la biodiversidad.

La comprensión de lo que es la biodiversidad obedece al marco ontológico empleado. Así, de un lado se encuentra la ontología disyuntiva que separa el ser humano de la biodiversidad y de otro lado la ontología de la continuidad entre el ser humano y la naturaleza (que incluye la biodiversidad) que concibe a ambos con el mismo nivel de importancia. Una perspectiva ontológica relacional habla del respeto a todas las manifestaciones de la vida por sus valores intrínsecos. La comprensión integrada entre el ser humano y la naturaleza (que incluye a la biodiversidad) obedece al reconocimiento que los seres humanos somos holobiontes, es decir somos una comunidad simbiótica entre células humanas y bacterias (bacterioma) sin las cuales no es posible la vida. Además, este carácter enfatiza el hecho que la cooperación es lo que prima (antes que mecanismos selectivos) y caracteriza a la vida en general (Maldonado 2019b:203). Desde este acercamiento propio de la Biocomplejidad no hay naturaleza ni cultura sino una única realidad (Maldonado 2019a:285). En esa misma perspectiva, Philipe Descola (2012), citado por Chávez (2020), considera que el dualismo entre cultura y naturaleza debe ser superado en tanto lo que existe son distintas formas de identificarse con ésta. Estos enfoques se ven corroborados a partir de la epigenética y la aproximación eco-evo-devo (relaciones entre la ecología, la evolución y el desarrollo) (Maldonado 2020b).

Existen muchas concepciones de lo que implica la biodiversidad, así se refiere a la variedad y variabilidad de las formas de vida sobre la tierra, silvestres y domesticadas (agrobiodiversidad) y la variación de la base hereditaria, se le considera una propiedad o atributo de los seres vivos de ser distintos o una característica de las múltiples formas de adaptación e integración de la especie humana a los ecosistemas de la tierra (McNeely et al. 1990).

Un campo específico de la biodiversidad refiere a la Diversidad Biológica Forestal. Desde una perspectiva antropocéntrica la Diversidad Biológica Forestal puede ser reducida a recursos naturales o capital natural en perspectiva del interés humano. Aunque el concepto de servicios ecosistémicos se incluye los servicios culturales por los beneficios espirituales y cul- 
turales que brindan esta formulación aún sigue siendo antropocéntrica y utilitarista (SCDB 2010).

Aunque la vida es un concepto que parece fácil, en realidad es un concepto muy difícil de precisar. A lo más se señalan características o atributos comunes tales como la reproducción, metabolización, procesamiento de información, capacidad de autonomía, procesos termodinámicos, adaptación y la combinación de estos atributos (Maldonado 2019a, 2021b) También hay quienes destacan la capacidad de autoorganización y las propiedades emergentes. La concepción de lo que es la vida también se ve afectada por el hecho que prácticamente no existe ninguna diferencia ontológica o material entre la vida y no vida y entre los factores bióticos de los abióticos, y que las diferencias son únicamente de grados, cualitativos o de organización (Maldonado 2016a, 2016b, 2019a). Como afirma Maldonado (2018:81):

Una buena comprensión de la vida y los sistemas vivos implica el reconocimiento explícito de una mutua y total codependencia entre los diversos niveles, escalas, formas y expresiones de vida, sin absolutamente ninguna centralidad o prioridad de ninguna especie sobre las demás.

Todo ello sustenta el hecho de hablar de derechos de la naturaleza que supera la premisa que el derecho solo es de humanos para los humanos.

Cuando se habla de diversidad biológica se está hablando específicamente de diversidad genética, específica (dentro de cada especie y entre las especies), estructural, ecosistémica y cultural. Así se habla entonces que los componentes de la biodiversidad son los genes, las especies de plantas, animales, hongos y microorganismos o protistos, los ecosistemas y sus procesos ecológicos (Convenio sobre la Diversidad Biológica - CDB, Artículo 2). El concepto ampliado de biodiversidad incluye la diversidad paisajística por tanto incluye los conceptos de territorios y de percepción. En ese caso es factible inscribir el concepto de biodiversidad en los conceptos de sistemas socioecológicos o de territorio y paisajes bioculturales.
Desde una perspectiva restringida la biodiversidad está asociada a la Biología, la Ecología, la Biogeografía, la Genética y la Taxonomía, entre otras. Desde una concepción ampliada la biodiversidad también está asociada, además de las anteriores, a la Antropología, la Filosofía, la Bioética, la Biología de la conservación, la Geografía, entre otras. Asimismo, amplía su visión para incluir disciplinas y corrientes, en pleno proceso de evolución como el Biodesarrollo, la Bioeconomía, la Biopolítica, el Bioderecho, entre otras.

La Meta 5 de Aichi para la diversidad biológica señalaba que:

Para 2020, se habrá reducido por lo menos a la mitad $\mathrm{y}$, donde resulte factible, se habrá reducido hasta un valor cercano a cero el ritmo de pérdida de todos los hábitats naturales, incluidos los bosques, y se habrá reducido de manera significativa la degradación y fragmentación. En ese sentido la Visión de la Diversidad Biológica para 2050 plantea, entre otras medidas, intensificar las iniciativas destinadas a conservar y restaurar la diversidad biológica en todos los niveles, usando enfoques que dependerán del contexto local (SCDB 2020:12).

Asimismo, señala que estas medidas:

Deben combinarse con grandes aumentos en la extensión y la eficacia de áreas protegidas bien conectadas y otras medidas eficaces de conservación basadas en áreas, la restauración a gran escala de hábitats degradados y mejoras en las condiciones de la naturaleza en los paisajes tanto agrícolas como urbanos (...) (SCDB 2020:12).

\section{Retos}

Según las Naciones Unidas, para evitar más pandemias se necesita controlar el tráfico ilegal de fauna y flora silvestre a través de un enfoque integral que centre en la oferta y la demanda y asegurando los medios de vida de las poblaciones locales (Quiñones 2020). Ello requiere un trabajo más colaborativo y articulado tanto al interior de los países como entre ellos. Aunque se ha sugerido la prohibición total de la caza de animales silvestres los especialistas señalan que esta medida sería contraproducente y que lo mejor sería una regulación pro- 
gresiva que tome en cuenta el bienestar de los animales, pero que tenga como finalidad última la desaparición del comercio de animales silvestres (Ortiz 2020).

La pandemia del coronavirus revela la conexión entre la salud humana y la naturaleza (ONU 2020). Si la relación de la humanidad con el planeta no cambia, las posibilidades de nuevas pandemias de origen zoonótico son muy elevadas (Daszak et al. 2020, Olguín y Núñez 2021). De ahí la importancia de la conservación de la biodiversidad para reducir el riesgo de la emergencia de futuras pandemias (SCDB 2020). Como señala FAO (2020:143), "para poder obtener resultados positivos tanto para la biodiversidad como para las personas, se ha de encontrar un equilibrio realista entre los objetivos de conservación y la demanda de recursos que sustentan los medios de vida". En este contexto los retos de las ciencias forestales refieren a una diversificación curricular orientada a establecer una mayor relación entre la pérdida de biodiversidad forestal y las pandemias, profundización sobre la relación entre las zoonosis y la gestión de bosques, adoptar transversalmente el enfoque de una salud que integra el abordaje de la salud humana, salud de los animales y de los ecosistemas y la salud planetaria (Cortés 2020). Asimismo, en el sector laboral es necesario que en los lineamientos de manejo forestal se incorporen aspectos relativos a reducir la posibilidad de zoonosis. Para ello es necesario que se trabaje con el apoyo de otras disciplinas especializadas en la salud humana y la salud animal.

Al respecto, la Declaración de Bridgetown emanada de la XXII Reunión del Foro de Ministros de Medio Ambiente de América Latina y el Caribe plantea:

Reconocer además que para reducir el riesgo de futuras enfermedades zoonóticas, tanto las presiones inmediatas como las subyacentes de la pérdida de la biodiversidad y de la degradación de los ecosistemas deben abordarse de manera integrada, eficaz, selectiva y sostenida y con los mayores niveles de cooperación internacional para enfrentar el tráfico de animales salvajes y la deforestación ilegal, reforzando al mismo tiempo la gestión forestal sostenible de conformidad con la legislación nacional (PNUMA 2021:6).

Conservar la biodiversidad es la clave para evitar nuevas pandemias, ello implica frenar la extinción de especies, conservar las áreas silvestres y promover esquemas de aprovechamiento genuina y profundamente sustentables (Pratesi et al. 2020). Asimismo, es necesario enfatizar la conexión entre los bosques y la salud humana (IRI 2020).

Para las ciencias forestales es un reto participar activa y propositivamente en la elaboración de alternativas al desarrollo en la perspectiva regenerativa. Eso implica repensar el enfoque fundamentalmente disciplinario que prima a la fecha.

\section{Discusión}

Es indudable que la formación y orientación disciplinaria de las ciencias forestales ha generado un importante conocimiento científico en la comprensión de los bosques, sus elementos y su dinámica. No obstante, los retos de la humanidad, que involucran a los bosques son muy complejos y por lo tanto el enfoque interdisciplinario, aunque necesario, resulta insuficiente. De ello da cuenta por ejemplo la crisis climática, la crisis del exterminio de la biodiversidad y los persistentes problemas de deforestación, tala ilegal, de comercio y tráfico ilegal de la fauna silvestre, entre otros.

Aunque el enfoque disciplinario forestal seguirá aportando significativamente al desarrollo forestal existe la necesidad de ampliar la mirada y reconocer que los temas relacionados a los bosques no se agotan solo en consideraciones biofísicas o cómo aportar mejor a la economía y al desarrollo. Las reflexiones derivadas del confinamiento por la pandemia del COVID-19 llevan a repensar las relaciones predominantes que hasta la fecha ha sostenido el ser humano con la naturaleza (con los bosques). Ello lleva a preguntarse ¿Cuál es el rol de las ciencias forestales en estos tiempos complejos? ¿Cuál es su gran propósito? ¿De qué economía o de qué desarrollo se está hablando? Las profundas reflexiones surgidas 
del confinamiento en todos los campos del conocimiento llevan a revisar teorías, enfoques, conceptos, definiciones, significados y sentidos que a la fecha se habían dado por sentados y que básicamente eran retos de implementación antes que de conceptualización. La realidad puesta en evidencia por la pandemia ha demostrado que hay mucho que repensar, recomponer y regenerar. En este contexto las ciencias forestales podrían aportar para evitar futuras pandemias con un mejor desarrollo del enfoque de paisajes forestales sostenibles en los que sea posible generar alternativas integradoras de gestión territorial en los que se toma en cuenta tanto dimensiones biofísicas como socioculturales y económicas cuidando siempre que la integración se fundamente en una sustentabilidad fuerte.

El enfoque disciplinario forestal, configurado por influencia y modelación de la economía y la política, ha llevado fuertemente a la concepción que los bosques son recursos naturales, recursos forestales, recursos genéticos, bienes ambientales, capital natural, servicios ecosistémicos que en esencia mantienen una impronta antropocéntrica. Aunque se hable de servicios culturales como parte de los servicios ecosistémicos estos son formulados en perspectivas del interés humano. Lo mismo pasa en la concepción de valor de existencia que "es un valor que se otorga a un bien ambiental y que no está relacionado con ningún uso ni actual ni futuro del bien" (Pérez 2016:12). Observe que la consideración es de bien ambiental y que forma parte de la clasificación de valor de no uso. En una perspectiva más biocéntrica sería importante que se destace del valor intrínseco de la vida. Una cosa es estar frente a un depósito de materia prima y otra cosa es reconocer que se está frente a un ser vivo o una comunidad de vida.

Pasar de la mirada de producto a una mirada de gestión territorial sostenible (y por tanto de paisajes forestales sostenibles) tiene grandes implicancias porque logra aportar significativamente en el desarrollo rural y al desarrollo urbano, logrando articularse a una serie de políticas, estrategias y planes que están vinculados al desarrollo económico y social entre los que se pueden destacar la alimentación, la energía, la salud, la educación, la generación de igualdad de oportunidades, la interculturalidad, entre otros tantos aspectos. Implica tener un rol más activo en la planificación y gestión territorial, en la gestión de cuencas, en la restauración de ecosistemas, entre otros. Asimismo, es una gran oportunidad para poner en valor los enfoques y principios de gestión ecosistémica y trabajar bajo la perspectiva de encuentro de culturas, conocimientos y saberes. Es cuando toma sentido hablar de bosques como socioecosistemas o incorporar la perspectiva de sistemas socioecológicos en el estudio y en la actuación forestal.

Incorporar además una perspectiva de valoración de todas las manifestaciones de la vida lleva a valorar las relaciones con todos los seres del planeta con el cual se forma una única comunidad de vida. Lo que implica ampliar la comunidad moral (moral extendida más allá de la sociedad humana) superando la visión exclusivamente antropocéntrica y utilitarista por una ética del cuidado, en otras palabras, incorporar la bioética forestal. Es cuando se puede prestar atención, hasta ahora evadidas, de los estudios animales, la neurobiología vegetal, entre otros tantos campos directamente relacionados con las ciencias forestales pero que permanecen distantes y ajenos.

Cierto es que la propia estructura política, económica, académica, social y cultural va en el sentido de la uniformidad, de funcionalidad hacia lo establecido, lo instituido, lo estandarizado, lo normalizado, lo cual es necesario revisar porque es precisamente esa forma de relacionarse entre los propios seres humanos y entre éstos y la naturaleza (los bosques), lo que ha llevado a la crisis actual y que la presente pandemia solo ha puesto en evidencia. En el lenguaje de la administración pública pesa muy fuerte temas como funciones, competencias, visión, misión, producción, productividad, competitividad, crecimiento económico, que ha sido asimilado por los decisores y operadores forestales, que dan poco margen para propuestas innovadoras. Es por ello la necesi- 
dad que las ciencias forestales se atrevan a incursionar en nuevos campos de estudio (como por ejemplo Ciencias de la Complejidad) para dar pie a la creatividad orientada a establecer nueva formas de relacionarse con la naturaleza (bosques) y no de ser más efectivos en su dominio y explotación.

La necesidad de una visión más amplia de las ciencias forestales está sustentada por las necesidades de un desarrollo diferente (o mejor a las alternativas al desarrollo). En otros campos como la biología por ejemplo ha habido un desarrollo exponencial que ponen en cuestión la forma misma cómo se ha concebido la vida y todas sus posibilidades. Estas discusiones, al privilegiar la mirada de producto, no están siendo aprovechadas por las ciencias forestales. Además, estos avances les dan un nuevo sentido a las propias ciencias forestales. Así como las ciencias sociales se predisponen a mejorar su interacción con las ciencias naturales es necesario que las ciencias naturales mejoren su nivel de articulación con las ciencias sociales (Chávez 2020). En el entendimiento actual de la realidad compleja las divisiones entre ciencias naturales y ciencias sociales son artificiales.

Se sabe ahora que la vida y los sistemas vivos son sistemas abiertos e incompletos que se relacionan recíprocamente con el entorno a través del intercambio de materiales, energía e información. En este sentido los sistemas vivos están en permanente procesamiento de información no algorítmica para poder responder a los cambios del entorno (Maldonado 2021b). Esta capacidad de escaneo, lectura, interpretación y respuesta es fundamental para la vida misma en todas sus escalas desde una célula hasta los ecosistemas. La compresión de los procesos de procesamiento de la información en los sistemas vivos alude a una disciplina científica transdisciplinaria llamada Hipercomputación Biológica (Maldonado 2016c, 2019b).

La pandemia del coronavirus, con todo el impacto sobre la humanidad, también ha brindado oportunidades para la reflexión y el reconocimiento de la necesidad de transformar la civilización hacia una orientación que sea más respetuosa de la vida en todas sus mani- festaciones, más colaborativa, más interrelacionada. Es también la oportunidad para que las ciencias forestales puedan incrementar su rol en la formulación de propuestas regenerativas. En los diversos foros virtuales de carácter ambiental, en los que ha participado el autor, ya se menciona la relación entre ecosistemas y pandemias, aunque en el sector forestal todavía no es explícita. De ahí la necesidad de llamar la atención al respecto para tomar medidas tanto a nivel de la academia como del sector laboral.

\section{Conclusiones}

Las evidencias científicas sustentan una estrecha interrelación entre la alteración y degradación de los ecosistemas (incluyendo los bosques) con las pandemias. Para evitar nuevas epidemias se requiere mejorar la relación entre los seres humanos y la naturaleza (los bosques), protegiendo y respetando la diversidad de formas de vida. Existen tres aproximaciones básicas de la relación entre las ciencias forestales con los bosques: una mirada de producto, una mirada de territorio y una mirada biocéntrica, las cuales consisten en respetar a todas las manifestaciones de la vida como su principal foco de pensamiento y acción. Aunque la orientación disciplinaria forestal ha sido y seguirá siendo importante para el desarrollo de las ciencias forestales, esta aproximación es insuficiente frente a la complejidad de la realidad y que tiene en los bosques un pilar fundamental. De ahí la necesidad de desarrollar las ciencias forestales desde la perspectiva de la complejidad, que hace más visible las interrelaciones de los bosques como socioecosistemas entendidos como sistemas abiertos, incompletos y alejados del equilibrio. Una mirada forestal de respeto hacia todas las manifestaciones de vida aumenta enormemente su campo de acción e impacto en perspectiva de las alternativas al desarrollo o un desarrollo regenerativo con bioética forestal.

\section{Referencias}

Altieri, MA; Nicholls, CI. 2020. La agroecología en tiempos del COVID-19 (en línea). Medellín, Colombia, CELIA. 6 p. Consultado 7 feb. 2021. 
Disponible en https://cauceecologico.org/ wp-content/uploads/2020/03/Marzo-18-2020CELIA-agroecologia-y-COVID19-2-1.pdf.

Álvarez, A. 31 may. 2020. Experto dice que la falta de gestión forestal influye en el origen de pandemias como la covid-19 (en línea, blog). Madrid, España, Efeagro. Consultado 9 feb. 2021. Disponible en https://www.efeagro.com/ noticia/experto-dice-que-la-falta-de-gestionforestal-influye-en-el-origen-de-pandemiascomo-la-covid-19/.

Arce, R. 2019a. Aproximaciones a la filosofía forestal de la sustentabilidad del manejo forestal en el Perú. Revista Forestal del Perú 34(2):113131. DOI: http://dx.doi.org/10.21704/rfp. v34i2.1322.

Arce, R. 2019b. Nuevas aproximaciones al manejo Forestal desde una perspectiva ética humanista. Paideia XXI 9(1):37-52.

Arce, R. 2020a. Contribuciones de las diversas perspectivas ecológicas a las ciencias forestales (en línea). Bosques Latitud Cero 10(2):85-98. Consultado 6 feb. 2021. Disponible en https:// revistas.unl.edu.ec/index.php/bosques/article/ view/848.

Arce, R. 2020b. Aproximaciones para el desarrollo de una bioética forestal a partir del caso peruano. Revista Latinoamericana de Bioética 20(1):107-122. DOI: https://doi.org/10.18359/ rlbi.4536.

Arce, R. 2020c. Contribución al desarrollo de la epistemología de las Ciencias Forestales. Revista Forestal Venezolana (62):85-100.

Arce, R. 2020d. Perspectivas ontológicas sobre los bosques. Revista Biotempo 17(1):47-59.

Arce, R. 2018. Complejidad y desarrollo forestal. Revista Forestal del Perú 33(2):102-116. DOI: http://dx.doi.org/10.21704/rfp.v33i2.1224.

Boff, L. 2020. Coronavirus: autodefensa de la propia Tierra. In Codina, V; Boff, L; Costadoat, J; Radcliffe, T; Moore, MP; Pagola, JA; Cotto, JJ; Vicini, A; Žižek, S; Costa, P; Han, B; Montecinos, S; Cyrulnik, B; Garretón, MA. COVID-19. Guadalajara, México, MA Editores. 118 p.
Campanella, E. 2020. Los asesinos invisibles. El Trimestre Económico 87(3):877-885. DOI: http://dx.doi.org/10.20430/ete.v87i347.1116.

Castro, M. 26 abril 2021. Unidad Funcional de Delitos Ambientales - UNIDA. (en línea, video). DAR. Herramientas, compromisos y retos para la protección de las personas defensoras de derechos humanos en el Bicentenario". Consultado 9 may. 2021. Disponible en https://www.facebook.com/aidesep/videos/920410508534095.

Chávez, J. 2020. Una ciencia social, ambiental y ecológica para la nueva convivencia. Revista de Sociología Rural Cambio Social 1(1):33-46.

Chomsky, N. 2020. Internacionalismo o extinción. 1 ed. Vasile, $\mathrm{P}$ (trad.). Buenos Aires, Argentina, CLACSO. 48 p.

Convenio sobre la Diversidad Biológica. Art. 2. 29 dic. 1993.

Cortés, ME. 2020. Enfermedad por coronavirus: la importancia de enseñar zoonosis bajo el enfoque de "Una Sola Salud". Investigación en Educación Médica 10(37) :108. DOI: https://doi.org/10.22201/facmed.20075057e.2020.35.202376.

Cué, F. 29 mar. 2020. Con los humanos confinados por el Covid-19, los animales recuperan terreno. (en línea, blog). France 24. Consultado 8 may. 2021. Disponible en https://www. france24.com/es/20200329-covid19-confinamiento-humanos-animales.

Daszak, P; Amuasi, J; das Neves, CG; Hayman, D; Kuiken, T; Roche, B; Zambrana-Torrelio, C; Buss, P; Dundarova, H; Feferholtz, Y; Földvári, G; Igbinosa, E; Junglen, S; Liu, Q; Suzan, G; Uhart, M; Wannous, C; Woolaston, K; Mosig Reidl, P; O’Brien, K; Pascual, U; Stoett, P; Li, H; Ngo, HT. 2020. Workshop Report on Biodiversity and Pandemics of the Intergovernmental Platform on Biodiversity and Ecosystem Services. Bonn, Alemania, IPBES. 108 p.

FAO (Organización de las Naciones Unidas para la Alimentación y la Agricultura, Italia); PNUMA (Programa de Naciones Unidas para el Medio Ambiente, Kenia). 2020. El estado de 
los bosques del mundo 2020: los bosques, la biodiversidad y las personas (en línea). Roma, Italia. 224 p. Consultado 9 feb. 2021 . Disponible en http://www.fao.org/3/ca8642es/CA8642ES. pdf.

Faccendini, AI. 2019. La nueva humanización del agua: una lectura desde el ambientalismo inclusivo. 1 ed. Buenos Aires, Argentina, CLACSO. 161 p.

Farpón, RF. 2018. Vive en verde, piensa en madera: los bosques frente a los objetivos de desarrollo sostenible. Asturias, España, Asmadera. $60 \mathrm{p}$.

Gabriel, M. 2020. El virus, el sistema letal y algunas pistas. In Agamben, G; Slavoj, Z; Nacncy, JL; Berardi, F; López, S; Butler, J; Badiou, A; Harvey, D; Han, B; Zibechi, R; Galindo, M; Gabriel, M; Yáñez, G; Manrique, P; Preciado, P. Sopa de Wuhan. Buenos Aires, Argentina, ASPO. p.129-134.

Gligo, N; Barkin, D; Brzovic, F; Durán, H; Gallopín, G; de Botero, MM; Ortiz, F; Pengue, W; Rofman, A; Sejenovich, H; Villamil, J; Alonso, G; Brailovsky, A; Carrizosa, J; Fernández, P; Leal, J; Morales, C; Panario, D; Rodríguez, M; Saa, R; Sunkel, O. 2020. La tragedia ambiental de América Latina y el Caribe. Santiago, Chile, CEPAL. 127 p. (Libros de la CEPAL, n. ${ }^{\circ}$ 161).

Harvey, D. 2020. Política anticapitalista en tiempos de coronavirus. In Agamben, G; Slavoj, Z; Nacncy, JL; Berardi, F; López, S; Butler, J; Badiou, A; Harvey, D; Han, B; Zibechi, R; Galindo, M; Gabriel, M; Yáñez, G; Manrique, P; Preciado, P. Sopa de Wuhan. Buenos Aires, Argentina, ASPO. p. 79-96.

Hidalgo, M. 2020. Influencia de factores geopolíticos en la aparición de brotes epidémicos. Madrid, España, IEEE. 27 p. Documento informativo.

IRI (Interfaith Rainforest Initiative). 2020. Bosques y pandemias: la protección de bosques tropicales puede evitar coronavirus y otras enfermedades emergentes. Manual para líderes religiosos y comunidades de la fe. Nairobi, Kenia, PNUMA.17 p.

Jeffries, B. 2020. La pérdida de la naturaleza y el surgimiento de pandemias: protegiendo la salud humana y planetaria. Bagordo, G (trad.). Gland, Suiza, WWF. 22 p.

Maldonado, CE; Gómez, NA. 2011. El Mundo de las ciencias de la complejidad: una investigación sobre qué son, su desarrollo y sus posibilidades. Bogotá, Colombia, Universidad del Rosario. 181 p.

Maldonado, CE. 2012. El biodesarrollo: saber qué se quiere y qué necesitamos como búsqueda de un modelo alternativo. Le Monde diplomatique (116):32-33.

Maldonado, CE. 2015. Pensar la complejidad, pensar como síntesis. Cinta de Moebio: Revista de Epistemología de Ciencias Sociales (54):313-324. DOI: http://dx.doi.org/10.4067/ S0717-554X2015000300008.

Maldonado, CE. 2016a. Complejidad de las ciencias sociales. Y de otras ciencias y disciplinas. Bogotá, Colombia, Ediciones Desde abajo. $309 \mathrm{p}$.

Maldonado, CE. 2016b. Hacia una antropología de la vida: elementos para una comprensión de la complejidad de los sistemas vivos. Boletín de Antropología 31(52):285-301. DOI: http://dx.doi.org/10.17533/udea.boan. v31n52a18.

Maldonado, CE. 2016c. Hypercomputación biológica y comunicación entre los seres vivos. Revista Simbiótica 3(1):207-229.

Maldonado, CE. 2018. Bioeconomía, biodesarrollo y civilización: un mapa de problemas y soluciones. In Eschenhagen, M; Maldonado, CE (eds.). Epistemologías del sur para germinar alternativas al desarrollo: debate entre Enrique Leff, Carlos Maldonado y Horacio Machado. Bogotá, Colombia, Universidad del Rosario. p. 69-93.

Maldonado, CE. 2019a. Las ciencias de la complejidad son ciencias de la vida. In Villegas, M; Caballero, L; Vizcaya, E. (eds.). Biocomplejidad: facetas y tendencias. Ciudad de México, México, Coplt-arXives p. 259- 295.

Maldonado, CE. 2019b. Educación e investigación en complejidad. Managua, Nicaragua, UNAN-Managua. 243 p. 
Maldonado, CE. 2020a. Occidente, la civilización que nació enferma. Bogotá, Colombia, Ediciones desde abajo. $151 \mathrm{p}$.

Maldonado, CE. 2020b. Tres lecciones que aprender de la crisis. Ludus Vitalis 28(53):115119.

Maldonado, CE (ed.). 2021a. Estética y complejidad: elementos para un estudio crítico del arte. Bogotá, Colombia, Creación-Arte \& Ciencia. 184 p.

Maldonado, CE. 2021b. Las ciencias de la complejidad son ciencias de la vida. 1 ed. Santiago, Chile, Trepen. 227 p.

McNeely, JA; Miller, KR; Reid, WV; Mittermeier, RA; Werner, TB. 1990. Conserving the world's biological diversity. Washington DC, Estados Unidos de Norteamérica, IUCN. 193 p.

Moutou, F. 2020. Las zoonosis, entre humanos y animales (en línea). Nueva Sociedad (288):90101. Consultado 7 feb. 2021. Disponible en http://aulavirtual.urp.edu.pe/bdacademicas/ scholarly-journals/las-zoonosis-entre-humanos-y-animales/docview/2435551426/ se-2?accountid=45097.

Olguín, M; Núñez, M. 25 ene. 2021. Predicen más pandemias ante pérdida de biodiversidad (en línea, blog). Ciudad de México, México. UNAM global. Consultado 8 feb. 2021. Disponible en https://unamglobal.unam.mx/predicen-mas-pandemias-ante-perdida-de-biodiversidad/.

ONU (Organización de las Naciones Unidas, Estados Unidos de Norteamérica). 22 may. 2020. La pandemia del coronavirus revela la conexión entre la salud humana y la naturaleza (en línea, blog). s.l. Consultado 8 feb. 2021. Disponible en https://news.un.org/es/story/2020/05/1474902.

Ortiz, G. 2020. Pandemias, zoonosis y comercio de animales silvestres (en línea). Revista de Bioética y Derecho (50):19-35. Consultado 8 feb. 2021. Disponible en http:// scielo.isciii.es/scielo.php?script $=$ sci arttext\&pid=S1886-58872020000300003\&1ng=es\&tlng=es.
Paz, J. 30 marz. 2020. Pumas, zorros y otros animales exploran ciudades latinoamericanas durante la pandemia del COVID-19. (en línea, blog). Mongabay. Consultado 8 may. 2021. Disponible en https://es.mongabay. com/2020/03/animales-silvestres-coronavirus-llegan-a-las-ciudades-de-latinoamerical.

Pérez, FJ. 2016. Medio ambiente, bienes ambientales y métodos de valoración. Equidad \& Desarrollo (25):119-158. DOI: http://dx.doi. org/10.19052/ed.3725.

PNUMA (Programa de las Naciones Unidas para el Medio Ambiente, Kenia). 2021. Declaración de Bridgetown. Reunión del Foro de Ministros de Medio Ambiente de América Latina y el Caribe $(22,2021)$. Bridgetown, Barbados. $13 \mathrm{p}$.

Quiñones, L. 10 jun. 2020. Para evitar más pandemias se necesita controlar el tráfico ilegal de fauna y flora silvestre (en línea, blog). s.l., Noticias ONU. Consultado 8 feb. 2021. Disponible en https://news.un.org/es/story/2020/07/1477241.

Resolución Ministerial 152 MINAGRI, 2020. Protocolo Sanitario Sectorial ante el COVID-19 en la actividad forestal. El Peruano. Lima, 29 jun.

Reynel, C; Terreros, S; Palacios, S. 2020. El herbario de la Facultad de Ciencias Forestales de la UNALM. Lima, Perú, UNALM. 100 p.

Robinson, NA; Walzer, C. 2020. Cómo evitar una nueva epidemia (en línea). Investigación y Ciencia (524):47. Consultado 7 feb. 2021. Disponible en http:// aulavirtual.urp.edu.pe/bdacademicas/scholarly-journals/cómo-evitar-una-nueva-epidemia/ docview $/ 2413817193 /$ se- 2 ? accountid=45097.

Santos, B. 2020. La cruel pedagogía del virus. 1 ed. Buenos Aires, Argentina, CLACSO. 88 p.

Santos, B. 2021. Lecciones iniciales de la pandemia de COVID-19. Revista de Economía Institucional 23(44):81-101.

SCDB (Secretaría del Convenio sobre la Diversidad Biológica, Canadá). 2010. La diversidad 
biológica forestal: el tesoro viviente de la Tierra. Montreal, Canadá. 48 p.

SCDB (Secretaría del Convenio sobre la Diversidad Biológica, Canadá). 2020. Perspectiva mundial sobre la diversidad biológica 5: resumen para los responsables de formular políticas. Montreal, Canadá. 19 p.

Pratesi, I; Galaverni, M; Antonelli, M; Asunción, M; Rivera, L; Suárez, L. 2020. Pérdida de naturaleza y pandemias: un planeta sano por la salud de la humanidad. Madrid, España, WWF. $18 \mathrm{p}$.

Tarazona, AM. 2020. Relaciones en tiempos de pandemia: COVID-19 y bienestar animal, ambiental y humano. Revista Facultad Nacional de Agronomía 73(2):3. DOI: http://dx.doi. org/10.15446/rfnam.v73n2.86957.

Varoufakis, Y. 2020. ¿Qué vendrá después del capitalismo?. 1 ed. Buenos Aires, Argentina, CLACSO. 54 p. 